\title{
Mixed farming diversification may be costly: southern Queensland case study
}

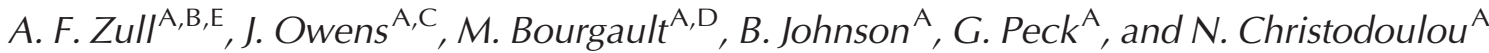 \\ ${ }^{A}$ Crop and Food Science, Queensland Department of Agriculture and Fisheries, Toowoomba, Qld 4350, Australia. \\ ${ }^{B}$ Australian Centre for Sustainable Business \& Development, University of Southern Queensland, \\ Qld 4350, Australia.

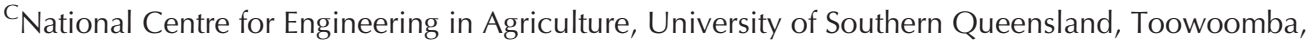 \\ Qld 4350, Australia. \\ ${ }^{D}$ Montana State University, Northern Agricultural Research Center, Havre, MT 59501-8412, USA. \\ ${ }^{E}$ Corresponding author. Email: andrew.zull@daf.qld.gov.au
}

\begin{abstract}
Many farmers in Australia and in other countries have a choice of crop or livestock production, and many choose a mixture of both, based on risk preference, personal interests, markets, land resources and local climate. Mixed farming can be a risk-spreading strategy, especially in highly variable climates, but the right scales of each enterprise within the mix may be critical to farm profitability.

To investigate expected farm profits, the probability of breaking even, as well as the worst and best case scenarios, we used farm data and APSIM (Agricultural Production Systems Simulator) to simulate the production of a typical, semi-arid, mixed-farm in southern Queensland. Three farming system scenarios were investigated: I, livestock and more intensive cropping; II, current production system of livestock and minimal cropping; and III, livestock only. We found that the expected profits were in the order system I > system III > system II. The key reason for the lower profits of system II was the high overhead cost of capital to continue some cropping, with low annual cropping income. Under the worst case scenario, in years with low rainfall, system I had the greatest downside risk with far greater financial losses. Systems I and III had similar probabilities of breaking even, and higher than system II, which incurs cropping overheads and limited cropping returns. Therefore, system II was less desirable than either system I or III. This case study helps farmers and advisors of semi-arid mixed farming enterprises to be better informed when making decisions at the paddock and whole-farm level, in both the short and long term, with respect to profit and risk. The method used in this paper can be applied to other mixed farms, in Australia and elsewhere.
\end{abstract}

Additional keywords: Dorper, flooding risk, prime-lamb, wheat.

Received 27 March 2016, accepted 17 March 2017, published online 27 April 2017

\section{Introduction}

A significant proportion of the world's land usage is dedicated to mixed crop-livestock farming, in the vicinity of 25 million $\mathrm{km}^{2}$, and nearly half of Australia's broadacre farm businesses use mixed crop-livestock production systems (de Haan et al. 1997; Bell and Moore 2012; Fisher et al. 2012). Australia has a long history of mixed farming, a result of high climate variability, infertile soils and variable landscapes, and to spread price variability risk of crops and livestock (Bell and Moore 2012; Bell et al. 2014b). Rainfed crop farming systems can extend to desert margins where rainfall can be extremely variable, resulting in both successful and failed crops. As such, livestock production has become an important element of cropping by reducing the risk of non-established crops or through grazing of failed crops (Connor 2004; Dunlop et al. 2004; Lloyd et al. 2009; Fisher et al. 2012).
Although many farms produce a mixture of crop and livestock, there is concern that farmers seeking higher income by specialising in cropping and reducing livestock numbers are increasing business risk (Hacker et al. 2009; Fisher et al. 2012; Bell et al. 2014b). This trend from livestock to cropping has in part been due to higher relative prices received for crops, increased use of technology, herbicides and synthetic fertiliser, as well as improved diversity and genetics of crops over the last 25 years (Connor 2004; Bell et al. 2014b). Reduced tillage and stubble retention has also decreased production costs and the risk of soil erosion. However, recent studies have suggested that current relative differences between crop and livestock commodity prices may be sufficient to slow or reverse this trend away from livestock (Bell and Moore 2012). Moreover, it was highlighted that past shifts in production had been overstated and livestock remains an important part of Australian cropping systems. 
Although cropping may produce higher profits in the shorter term, continued cropping can adversely affect the long-term sustainable production potential of the land. Long-term cropping can become unsustainable because of declining soil organic matter, soil structural degradation, nutrient rundown (through removal in crop products) and excessive deep drainage (and salinity risk) (Silburn et al. 2007; Biggs et al. 2010; Bell et al. 2014a). Well managed pastures of grasses and legumes can improve soil physical properties by increasing soil organic matter and biological fixation of nitrogen with legumes; moreover, perennial grasses can reduce deep drainage and higher levels of groundcover can reduce soil erosion (Silburn et al. 2007). Intensive cropping with persistent herbicide usage can also increase selection pressure of herbicide-resistant weeds (Powles et al. 1996). In situations of high herbicide-resistance pressure, occasional longer pasture phases ( $\geq 3$ years) have shown to be financially and agronomically beneficial (Monjardino et al. 2004).

Rainfall is highly correlated with variability in rainfed crop and pasture production, which in turn affects farm annual profits and business equity (Lawes and Kingwell 2012). One cropping strategy is to seek to maximise profits (defined here as total income less total costs excluding company tax payments) in years with full soil-moisture profiles to produce high yields, and minimise losses in low-rainfall seasons by planting crops only when a certain soil moisture threshold has been reached. However, many Australian farmers are risk-averse and seek to reduce farm income variability by combining crop and livestock production (Bardsley and Haris 1987; Connor 2004; Bell and Moore 2012; Lawes and Renton 2015). Economies of scale for cropping and livestock-production enterprises then need to be sought, based in part on available resources, markets, personal expertise and preferences; there is an element of mutual exclusiveness - as one enterprise area increases the other tends to decrease. Lawes and Kingwell (2012) analysed economic and production survey data from 123 Western Australian mixedfarms (2005-09, which included drought years) and found that higher portions of cropped area provided greater opportunity to capitalise on favourable climatic conditions and improve farm financial health. By contrast, a case study in Temora, New South Wales (Bell and Moore 2012), found that devoting 40\% of farm area to cropping resulted in the lowest coefficient of variation in whole-farm gross margins. However, it may be impractical to have such a high portion of the farmland dedicated to cropping, because of localised climatic or soil conditions. Soil degradation from long-term cropping can decrease both production and economic performance on shallow, fragile soils (Silburn et al. 2007). This has resulted in some farms having traditional cropping land converted to pasture, including Red Kandosol soils south of St George, Queensland. This region is considered subtropical rangeland, tending to have summerdominant rainfall, averaging $\sim 500 \mathrm{~mm} /$ year (BoM 2012; Bell et al. 2014a). Many farms in this region have mosaic soil types across their farm, limiting the capacity to intensify cropping at the paddock level. These production constraints may restrict the proportion of land being cropped and therefore the benefits of mixed farming.

Mixed farming systems are more complex than farms based solely on either cropping or livestock enterprise (Price and
Hacker 2009). Therefore, the question must be asked, when is it still worthwhile to have a mixture of crop and livestock production, especially with respect to decreasing economies of scales on farm capital for decreased cropping? An alternative strategy in semi-arid regions is to consider specialising solely in livestock production.

Many whole-farm case studies report the expected profits but ignore risk. Farm production decisions in mixed farming systems are based on not only the expected profits but also the associated production risk and lifestyle choices (Makeham and Malcolm 1981). We used a combination of modelling and data from a case-study farm near St George in southern inland Queensland, where both grain and livestock (wool, sheep and cattle) production are common, to investigate the expected profits and risk of different production systems. This analysis sought to investigate the importance of both profit and risk when selecting enterprise sizes within a mixed farming system. The results of this study can help mixed crop-livestock farmers to be better informed when making their on-farm decisions in the short and longer term (10 years) with respect to mitigating risk and changes in profits through enterprise economies of scale of area.

\section{Methods}

Three semi-structured interviews (2012-13) were conducted with the farm owners, aimed at understanding their production system, farm operations and factors of production.

The 11000-ha case-study property was in the St George region, southern Queensland. A major constraint of crop production in the region is the low annual rainfall $(\sim 500 \mathrm{~mm})$, which is also highly variable with a range of $175-975 \mathrm{~mm} /$ year (BoM 2012). The climate has a summer-dominant rainfall pattern; the large moisture deficits from September to April result in a preference for winter crops such as wheat and chickpeas (Robinson et al. 2010). The case-study property has been operated by the same family since the 1900s. In the 1980s, pastures were cleared for wheat and chickpea production (Biggs et al. 2010). As with most farms, the production system has constantly changed with changes in markets, technology, lifestyles, and input and output prices. In recent years, some sheep farmers (including this case-study farmer) have moved away from wool-sheep, in part due to increased labour costs and lower wool prices, to prime-lamb production of non-wool breeds (e.g. Dorpers). Similar decisions have been made about the intensity of cropping within their systems. In this case study, the family has decreased crop intensity (area) because of production risk, personal preference towards sheep-livestock, and unwillingness to 'spend time in a tractor'. The property is adjacent to the Moonie River, and is therefore subject to flooding, as can be seen by the grey alluvial soil in Figs 1 and 2. Flooding events can assist in filling the soil moisture profile but can also damage established crops and pastures, especially when heavy flood events persist for many weeks (due to water being trapped within paddocks). Limited historical data were available on flooding in the region, especially during early last century. Livestock production on this case-study farm was a sheep breeding-replacement system, where only the rams were purchased from markets. Through interviews, the primary 


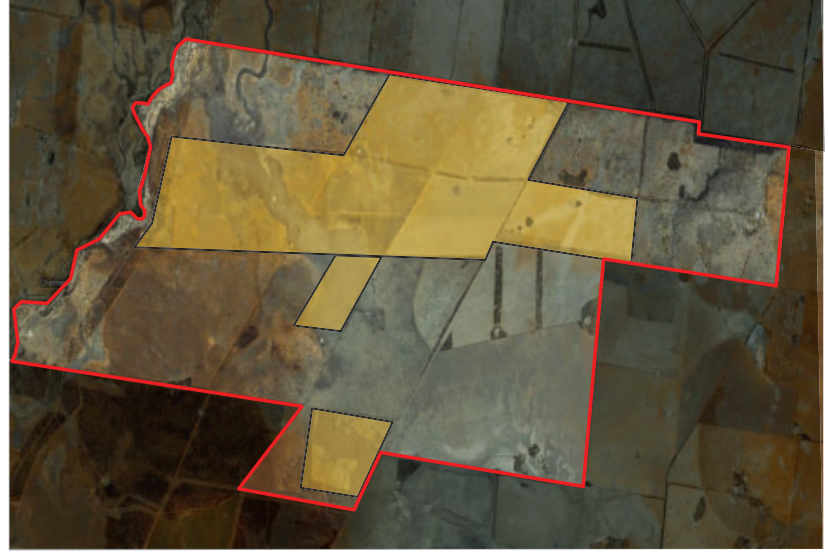

Fig. 1. Case-study property map under production system I, where the shaded areas are used for crop rotations. The remaining areas, being both native and improved pastures, are used for livestock production. This scenario is based on earlier (1980s) cropping practices on the case-study farm.

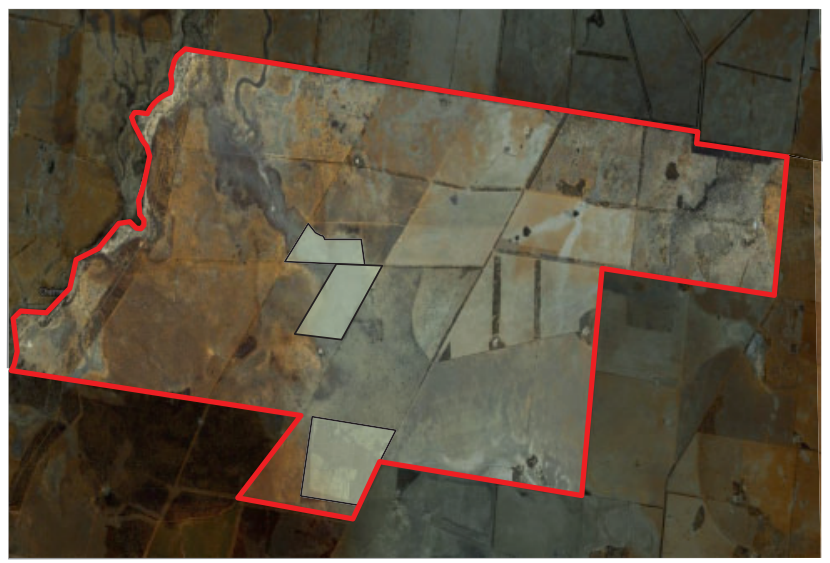

Fig. 2. Same case-study property under production system II, where the shaded areas are used for crop rotations. The remaining areas, being both native and improved pastures, are used for livestock production. This scenario was based on current cropping practice on this case-study farm. Production system III operates on the same total area solely for livestock production.

production risk drivers were ascertained as climatic: floods, droughts, and frosts.

\section{Case-study farm scenarios}

To investigate the expected production, profits and risk, we established three production scenarios typical for the region, any one of which can be used with little change to capital infrastructure: system I, more intensive cropping, $30 \%$ of land used for crop rotations (Fig. 1); system II (current production system), minimal cropping, $5 \%$ of land used for crop rotations (Fig. 2); system III, livestock only: none of the land area used for crop rotations.

\section{Farmer survey}

Based on farm records and regional practices, the overheads of production systems I and II were estimated to be $\sim$ AU $\$ 365000 /$ year (Table 1). System III, which excluded crop production,
Table 1. Annual overheads for production systems on the case-study farm

\begin{tabular}{lcc}
\hline Costs & \multicolumn{2}{c}{ System } \\
& I and II & III \\
\hline Administration & $\$ 33000$ & $\$ 33000$ \\
Rates & $\$ 12000$ & $\$ 12000$ \\
Non-farming costs: electricity, fuel, & $\$ 15000$ & $\$ 15000$ \\
$\quad$ depreciation, insurance, motor vehicles, etc. & & \\
Farming equipment depreciation & $\$ 30000$ & $\$ 10000$ \\
Repairs and maintenance (other than & $\$ 50000$ & $\$ 45000$ \\
$\quad$ those included as variable costs) & & \\
Regrowth control & $\$ 15000$ & $\$ 15000$ \\
Other (including seed grading) & $\$ 20000$ & $\$ 15000$ \\
Allowance for unpaid labour & $\$ 50000$ & $\$ 50000$ \\
Permanent wages & $\$ 140000$ & $\$ 140000$ \\
Total & $\$ \mathbf{3 6 5 0 0 0}$ & $\mathbf{\$ 3 3 5 0 0 0}$
\end{tabular}

required less farming equipment and associated repairs; therefore, overheads were decreased by $\$ 30000$ to an estimate of $\$ 335000 /$ year.

Because many farms have different levels of debt, this analysis did not include debt, and all capital was fully owned. However, there was an opportunity cost associated with full ownership, because that capital could be invested elsewhere. The total capital value of the property was estimated at $\$ 8$ million, and if invested at $5 \%$ per year, the annual opportunity cost was $\$ 400000 /$ year.

\section{Biophysical simulation modelling: APSIM and GRASP}

Agricultural Production Systems Simulator (APSIM), based on 111 years of climatic data (1900-2011), was used to estimate production variability of the case-study farm (Keating et al. 2003), and coupled with an economic production function, we estimated the associated profit and risk. Results included possible levels of production over time for the different systems, and the probability of breaking even, as well as the effects of very good and bad years. Perennial grass production was modelled by using the Grass Production Model (GRASP) in APSIM. GRASP is a deterministic, one-dimensional model of native pastures in semiarid and tropical grasslands (Rickert et al. 2000).

\section{Case-study data \\ Soil data}

On the case-study property, the higher elevation areas and ridges have Red Kandosols. These soils have a high infiltration rate and low water-holding capacity (Figs 1 and 2). The lower areas on the property are Grey Dermosols (clays). These soils have higher water-holding capacities and low infiltration rates. Even with summer fallows to store soil moisture, wheat production was unlikely to be viable in low-rainfall years. The soil-water data for this property were based on the study by Christodoulou et al. (2001), with the plant-available water capacity of $110 \mathrm{~mm}$ for the Grey Dermosol and $60 \mathrm{~mm}$ for the Red Kandosol. Using satellite imagery and farmer interviews, each paddock was proportioned into red or grey soils. Naturalised buffel grass (Cenchrus ciliaris) pasture was primarily on the lighter red soils, and predominantly Mitchell grass (Astrebla sp.) and Queensland bluegrass (Dichanthium sericeum) on the heavier clay soils. 


\section{Climatic data}

This farm is in a semi-arid, subtropical rangeland region, with summer dominant rainfall (Bell et al. 2014a). Daily climatic data for the site at coordinates $28.20^{\circ} \mathrm{S}, 148.90^{\circ} \mathrm{E}$ were used for the biophysical modelling (Fig. 3; BoM 2012).

\section{Crop production}

The sowing rules for chickpea and wheat in both the Grey Dermosol and Red Kandosol soils used for APSIM are given in Table 2. To simplify the cropping sequence, all cropped paddocks were modelled with 10-year rotations: chickpea 1 year, wheat 3 years, lucerne 5 years and long fallow 1 year. To overcome the possibility of biasing the results by having good years for a particular stage of the rotation and paddock, we phased paddock rotations. This involves dividing the cropping area (Figs 1 and 2) into ten equal portions, one for each of the rotation stages.

Each paddock was described by size, production purpose (cropping or solely livestock production) and the proportions of grey and red soils. Based on the farmer's records, production levels (low, expected and high) were recorded and used to validate model inputs and outputs. The lucerne rotations were used for livestock production. Lucerne was used as a perennial pasture that was sown with the last wheat crop in the rotation, but because of the limited regional rainfall and flooding events, it performs poorly as a crop and had similar forage capacity as the Queensland bluegrass and naturalised buffel and Mitchell grasses.

\section{Livestock production}

Feed availability can affect animal maintenance, liveweight gains and wool growth, as well as conception, lambing,

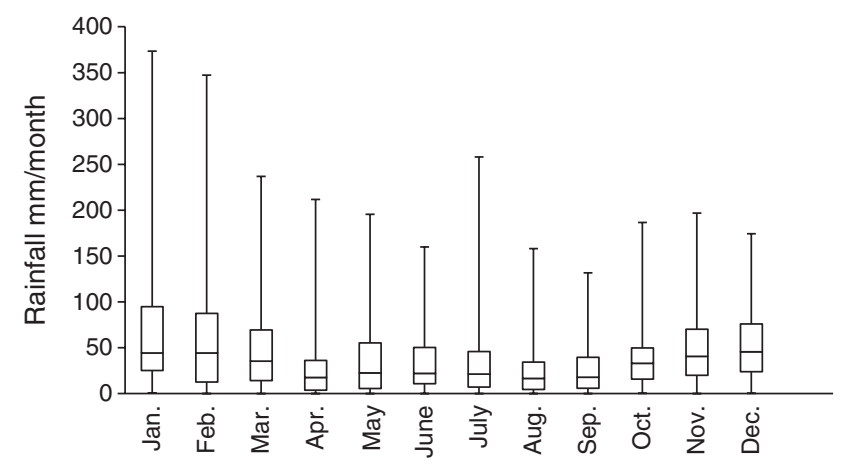

Fig. 3. Seasonal rainfall data from St George region (1900-2012; BoM 2012). Boxes depict the 25 th, 50 th and 75 th percentiles and whiskers the 0 and 100 percentiles. The average annual rainfall (January-December) was $499 \mathrm{~mm} /$ year (not shown in graph), with a minimum $175 \mathrm{~mm}$ in 1901 and maximum $975 \mathrm{~mm}$ in 1950 . weaning and lamb mortality rates (Pitta et al. 2005). Compared with other sheep breeds, Dorpers are generalist feeders that can utilise low-quality diet plants species; this helps them to survive and reproduce under harsh conditions (Cloete et al. 2000; Alemseged and Hacker 2014). Rangeland livestock systems in this case-study region are primarily supported by summer-active grasses and perennial shrubs (Bell et al. 2008). These extensive production systems often operate on conservative stocking rates, with the aim of reducing the downside risk of feed deficits and the associated supplementary feed costs (Bell et al. 2008, 2014a). On this case-study farm, there were $\sim 5000$ ewes on 11000 ha; including lambs, this was an average stocking rate of $<1$ dry sheep equivalent (DSE)/ha. Because the farm uses low stocking rates and feed was expensive to obtain in poorer years, supplementary fodder is not used. Pitta et al. (2005) investigated sheep performance under drought conditions in New Zealand and showed that droughts result in liveweight losses in ewes (however, no increase in mortality was recorded) and reduced conception, twinning, lambing, weaning and lamb survival rates. Weaners will typically achieve the market target liveweight of $>35 \mathrm{~kg}$ within 6 months of birth (Cloete et al. 2000). In seasons of low feed availability, the case-study farm typically holds sheep 1-2 months longer until target weights are achieved. We have used an average annual mortality rate of $3 \%$ for sheep $\geq 1$ year old, and with the farm's conservative stocking rate, it is unlikely that mortality rates of sheep will change much, even in poorer seasons. Meat production is the sole income from non-wool sheep; therefore, reproduction rates are particularly important (Cloete et al. 2000). Accelerated Dorper mating programs (ewes mating more than once per year) have average lambing rates of $\sim 1.46$ lambs/ewe. year (Cloete et al. 2000; Alemseged and Hacker 2014). However, the case-study farmer indicated that conception rates and lactation will decrease below the average when there is insufficient feed. Although Alemseged and Hacker (2014) and Schoeman (2000) reported multiple births (i.e. twining), lambing and joining rates were not provided. The case-study farm uses an accelerated-breeding management program of two joinings per year. Lambing rates ranged from 0.6 to 2.1 lambs/ewe.year, largely according to climatic conditions and associated grass biomass production. The upper lambing rate has been achieved on this property through focusing on the twinning trait of their Dorpers. In good years of high grass biomass, $40 \%$ of the ewes will have twins that survive through weaning one or two times per year, and all ewes were pregnant (all non-pregnant ewes were put back in the ramming paddock or sold). In poor years with low biomass, the probability of twinning decreases, and even if a ewe twins, the likelihood of both twins surviving is very low.

Table 2. Sowing rules of crops used for APSIM

\begin{tabular}{|c|c|c|c|c|c|c|c|c|}
\hline Crop & Cultivar & Planting window & $\begin{array}{l}\text { Must } \\
\text { sow? }\end{array}$ & $\begin{array}{l}\text { Min. rainfall } \\
\quad(\mathrm{mm})\end{array}$ & $\begin{array}{l}\text { No. of } \\
\text { rainfall days }\end{array}$ & $\begin{array}{c}\text { Min. soil } \\
\text { water }(\mathrm{mm})\end{array}$ & $\begin{array}{l}\text { Row spacing } \\
(\mathrm{mm})\end{array}$ & $\begin{array}{c}\text { No. of plants } \\
\text { per } \mathrm{m}^{2}\end{array}$ \\
\hline Chickpea & Amethyst & 15 May-15 June & No & 15 & 5 & 50 & 500 & 30 \\
\hline Wheat & Hartog & 15 May-15 June & No & 15 & 5 & 50 & 250 & 100 \\
\hline
\end{tabular}




\section{Commodity and variable cost price data}

The variable input costs and output selling prices are given in Table 3. All prices are presented in Australian dollars in 2013.

\section{Economic model: whole-farm profits and net present values}

The profit $(\pi)$ production function used in our analysis was:

$$
\pi_{t}=\left(\left(Y_{G t} \times P_{G}\right)-C_{G t}\right)+\left(\left(Y_{S t} \times P_{S}\right)-C_{S t}\right)-C_{F}
$$

where $P_{G}$ and $P_{S}$ are the selling price of grain and prime lamb (sheep), $Y_{G t}$ and $Y_{S t}$ are the total grain and sheep production in year $t$ (1900-2011), $C_{G t}$ and $C_{S t}$ are variable costs of grain and sheep in year $t$, and $C_{F}$ is the fixed cost (overheads). Note that this study examined only what would be the likely profit in today's value if the climatic conditions in year $t$ occurred. Therefore, the changes in the $C_{t}$ are based not on the cost in year $t$, but rather on what the current variable cost would be under the climatic conditions of year $t$ and the resulting level of production. Moreover, the selling price $(P)$ and overheads $\left(C_{F}\right)$ were fixed and did not change with respect to climatic conditions or the associated on-farm production and were therefore assumed timeindependent. In reality, commodity prices do change over time, and climatic conditions may affect prices. During droughts, for example, livestock prices may initially be driven down due to farmers destocking properties, and later, prices may increase with reduced meat supply. This temporal price relation function to climate was unknown for the different commodities; therefore, we undertook a price-sensitivity analysis to investigate possible price risks to the different production systems.

\section{Case study: input and output prices of production}

Crop variable costs per crop and year were:

$$
C_{G t}=C_{G_{1}} \times \text { area }_{t}+C_{G_{2}} \times Y_{G t}+C_{G_{3}} \times \mathrm{MAPkg}_{t}
$$

which was driven by the size of area cropped, yields and the amount of nitrogen required by crops (derived by APSIM) at time $t$. The only fertiliser applied on the farm was mono-ammonium phosphate (MAP), which consists of $10 \%$ nitrogen. The cost of mechanically applying fertiliser has been included in the variable costs in Table 3. The quantity of fertiliser was varied from year to year owing to season conditions and for different crops. Additionally, if there was a non-planting year or a failed crop, an extra $\$ 15 /$ ha was included for weed control for that year, but no other production costs.
To model the probability of joining and twinning we used an upper and lower threshold, based on available feed derived from APSIM-GRASP daily total standing biomass and averaged per calendar year. The upper lambing rate threshold was set at the 80 th percentile of total standing dry matter $(3840 \mathrm{~kg} \mathrm{DM} / \mathrm{ha})$ over the 111 years of data. This upper threshold was set for the years of exceptional grass production when the amount of feed exceeds demand. The lower lambing rate threshold represents drought conditions, and was set at the 10th percentile mark $(1039 \mathrm{~kg} \mathrm{DM} / \mathrm{ha})$. The reason for this lower threshold was that livestock supplement their usual feed by seeking feed from other areas or even less desirable feed.

Annual prime-lamb sale $\left(Y_{S t}\right)$ for all systems was calculated as:

$$
Y_{S t}=\left(\sum_{i=1}^{i=5} R \times(1-d)^{i-1}\right) \times L_{t}-R+R(1-d)^{4}
$$

where

$$
L_{t}=f\left(B_{t}\right) \text { and } 0.6<L_{t}<2.1
$$

where $R$ is the average annual replacement ewes of the different systems, $d$ is the annual death rate $(3 \%), i$ represents the age of ewes, and $L_{t}$ is the lambing rate in year $t$ and is a function of grass biomass $(B)$ in the same year. Note that the replacement ewes were removed from the sales, and the retiring ewes ( 5 years old) were added to sales figures. The value of $R$ was set at 1011, 1145 and 1151 for systems I, II and III, respectively. This resulted in steady-state flocks of ewes (after selling lambs and replacements) being 4760,5390 and 5420 for the respective systems. There was little difference in the stocking rates of the three systems due to half of the crop rotations being lucerne fodder for livestock production.

Although rangeland systems operate on long time scales, farmers operating within these systems rarely base their production decision beyond a decade. To investigate the risk of having concurrent good or bad years, we looked at the net present value (NPV) of profits for a moving decade, using:

$$
\mathrm{NPV}_{t}=\sum_{z=0}^{z=9} \pi_{t+z}(1+r)^{-z}
$$

starting in year $t$ (1900-2001), with a discount rate $(r)$ of $7 \%$; $z$ was the year within the 10 -year horizon, and $\pi$ was the profit in year $t+z$, given in Eqn 1 .

Table 3. Variable costs of inputs and selling prices of outputs in 2013, used for the case-study farm production

\begin{tabular}{|c|c|c|c|c|c|}
\hline & Wheat & Chickpea & & Lambs & Ewes \\
\hline \multicolumn{6}{|c|}{ Variable costs } \\
\hline$C_{G_{1}}$ (growing) $(\$ / \mathrm{ha})$ & 87.95 & 147.41 & $C_{S}$ (veterinary) $(\$ /$ head $)$ & 4.49 & 3.62 \\
\hline$C_{G_{2}}($ cartage $)(\$ / \mathrm{t})$ & 20.00 & 20.00 & $C_{S}($ cartage $)(\$ /$ head $)$ & 1.50 & 1.50 \\
\hline$C_{G_{3}}(\mathrm{MAP})(\$ / \mathrm{kg})$ & 0.98 & 0.98 & & & \\
\hline \multicolumn{6}{|c|}{ Selling prices } \\
\hline$P_{G}(\$ / \mathrm{t})$ & 250 & 350 & $P_{S}(\$ /$ head $)$ & 90 & 90 \\
\hline
\end{tabular}
systems

Production costs for crops exclude mono-ammonium phosphate (MAP) costs. Growing costs are higher for chickpea than wheat because of higher seed prices and crop-protection costs. Costs include fuel, oil, repairs and maintenance of planting and spraying equipment. Contracted harvesting is used for both crops 


\section{Risk considerations of production systems}

The primary climatic risks were floods, droughts and frosts. Although the same family has managed the case-study farm for many decades, not all frosting, rainfall and flood events were recorded or quantified. To estimate the risk (variability) of production due to these events, we used historical climate data from St George and APSIM modelling to estimate the timing and severity of these events.

\section{Flood risk}

The farm owners stated that the farm floods one year in ten, and this often coincides with heavy localised and upstream rainfalls (in the Tara region, Q1d). We used rainfall records and recorded river levels to help to estimate flooding events for two periods (Fig. 4):

1. From 1900 to 1969 , we used the farmer's family observations of flood events, which had coincided when Tara had $>70 \mathrm{~mm}$ rainfall over 5 days and the farm had $>110 \mathrm{~mm}$ rainfall over 5 days (BoM 2012).

2. From 1969 to present, we used Moonie River levels, based on Queensland Department of Environment and Resource Management data (DERM 2012) from Station 417201B; flooding coincides with the river heights $>5.5 \mathrm{~m}$.

Post-flooding, parts of the paddocks can remain under water for many weeks and even months. When a flooding event occurred, the modelled wheat and chickpea crops on the grey soils were considered failed crops because they were destroyed or the ground was too wet to plant and/or harvest. When a flood event occurred, the biomass of fodder production from both buffel grass and lucerne was reduced by $15 \%$ on the grey soils. The crops and forage pastures on the red soil portions of paddocks, which were on higher ground, were assumed to be unaffected by floods. Most paddocks have some red soil, so all planted paddocks had some crop production.

\section{Drought risk}

APSIM was used along with historical climate data (1900-2012) to estimate the possible range of wheat, chickpea and pasture grass production, using current farm production technology, practices and soil properties.

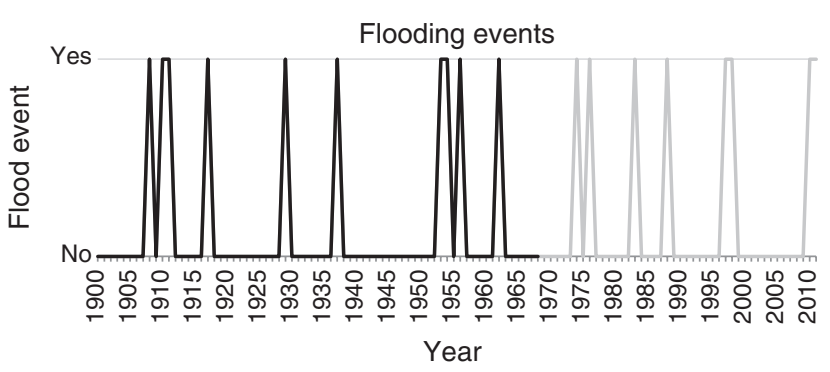

Fig. 4. Modelled flooding events based on the farm owners' observations on the probability of flooding (1900-69), using rainfall data from Tara and St George region (BoM 2012), as well as river data (1969-2011) for the Moonie River at Nindigully (DERM 2012).

\section{Frost risk}

Frost damage was a major risk to winter crops in the region. Within APSIM, frost-damaged base leaf senescence, grain abortion or reduced grainfill (leading to screenings and low quality) commences when temperatures fall below $-5^{\circ} \mathrm{C}$ and therefore decreases crop yields (Keating et al. 2003).

\section{Price risk}

The other risk was price changes for outputs, and the sensitivity of the systems to these changes. A large portion of Australia's meat and grain production is exported (DoA 2014), and therefore, both demand and prices are driven by international commodity markets. The prices used in this analysis (Table 3) were based on the case-study farmer's expected farm-gate selling prices in 2013 as a reflection of prices received in previous years. Using FAO data (available up to 2012) in US\$/t for sheep meat, wheat and chickpea (FAO 2016), and then converting them into AU\$/t, and adjusting for inflation with the Australian Consumer Price Index (RBA 2016), we were able to obtain the historical prices over time at 2012 price level (Fig. 5).

Between 1991 and 2012, there was a clear correlation in real price movement between wheat and chickpea; however, they do not appear to correlate to a movement in sheep meat prices (Fig. 5). The real-price trend over this period was increasing for sheep meat (AU\$133/t.year), and slightly decreasing for wheat $(-\$ 2.57 /$ t.year $)$ and chickpea $(-\$ 4.84 /$ t.year $)$. The median annual real-price fluctuation was $15.5 \%, 13.9 \%$ and $11.9 \%$ for sheep meat, wheat and chickpea, respectively (Fig. 6). Wheat displayed the greatest total volatility with the doubling of wheat prices in 2008 and then halving in 2009; however, it was also the most stable for most years ( 0 to 75 th percentiles).

\section{Results}

\section{Crop production}

Annual production of wheat and chickpea was highly variable compared with livestock production. The distribution of production at the whole-farm level for systems I and II is presented in Fig. 7. System II is the current production system and system III has no crop production. The expected (median) production values for systems I and II, respectively, were

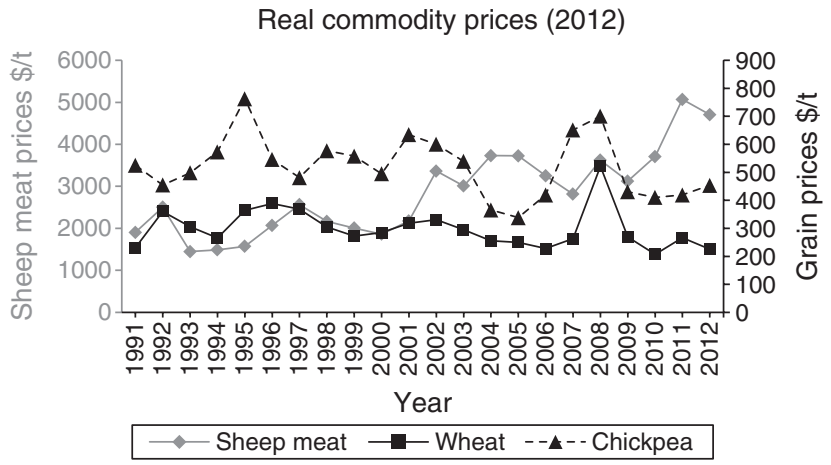

Fig. 5. International prices of sheep meat, wheat and chickpea 1991-2012 (FAO 2016), adjusted from US\$ to AU\$ (RBA 2016) and by Australian Consumer Price Index at 2012 (RBA 2016). 


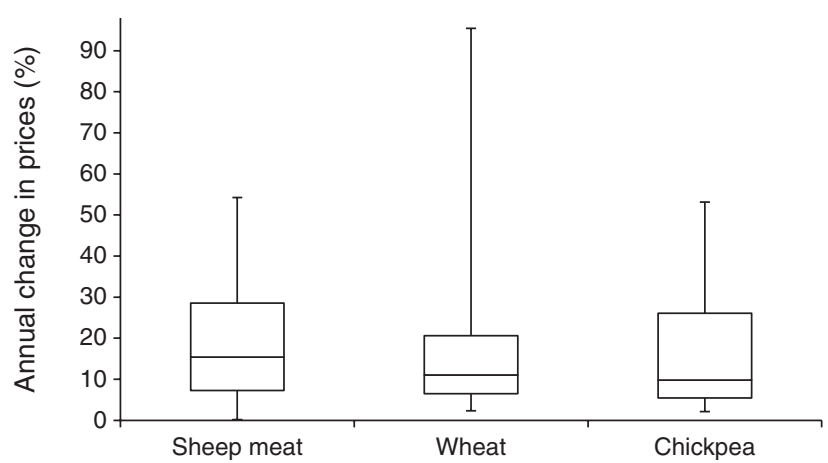

Fig. 6. Annual international price volatility for sheep meat, wheat and chickpea 1991-2012 (FAO 2016), adjusted from US\$ to AU\$ (RBA 2016) and by the Australian Consumer Price Index at 2012 (RBA 2016). Median annual price change $15.5 \%, 13.9 \%$ and $11.9 \%$ for sheep meat, wheat and chickpea. Boxes depict the 25 th, 50 th and 75 th percentiles and whiskers the 0 and 100 percentiles.

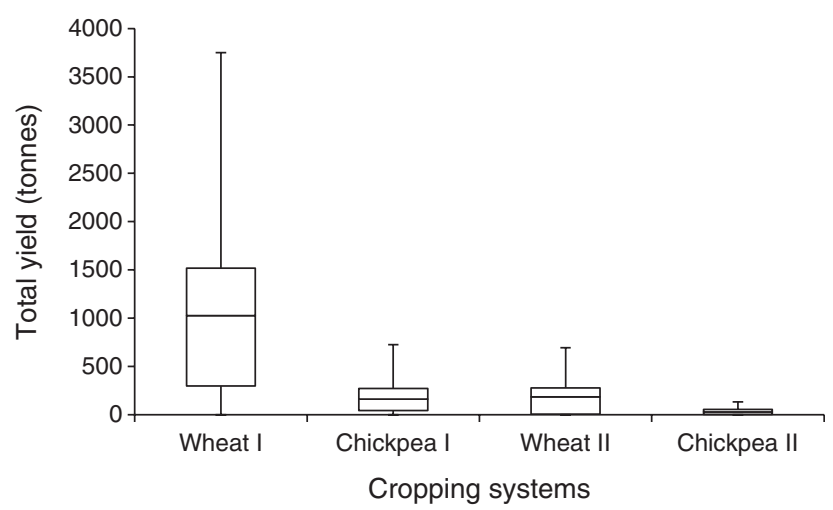

Fig. 7. Variability of simulated total crop production for wheat and chickpea in system I (Wheat I and Chickpea I) and system II (Wheat II and Chickpea II), using current technology and farm practices with climatic conditions observed from 1900 to 2011. Zero yield values (tonnes of grain) indicate nonplanting years and failed crops. Boxes depict the 25th, 50th and 75th percentiles and whiskers the 0 and 100 percentiles.

1026 and $186 \mathrm{t}$ for wheat and 163 and $29 \mathrm{t}$ for chickpea. All had a possibility of zero production. This was reflected in the coefficients of variation (CV) being $0.80,0.89,0.88$, and 0.96 for wheat I, chickpea I, wheat II and chickpea II, respectively, compared with sheep I, II, and III, all with a CV of 0.39 (Fig. 8). The decreasing shift in crop production from system I to system II was primarily due to less land being used for grain production. Other background drivers include lower yields on the Red Kandosols (which were more dominant in system I) and potential flooding events on the lower lying Grey Dermosols (which dominate system II). Results indicated very little, if any, grain for $\sim 15 \%$ of years (zero on the $x$-axis) due to non-planting or failed crops (including flooding). Total wheat production was greater than chickpea production, due to a higher proportion of land being used for wheat and higher wheat yields per hectare; there were three wheat crops and a chickpea crop in a rotation. Average wheat yields (including non-yielding years) on red and grey soils were 1.0 and $1.3 \mathrm{t} / \mathrm{ha}$.

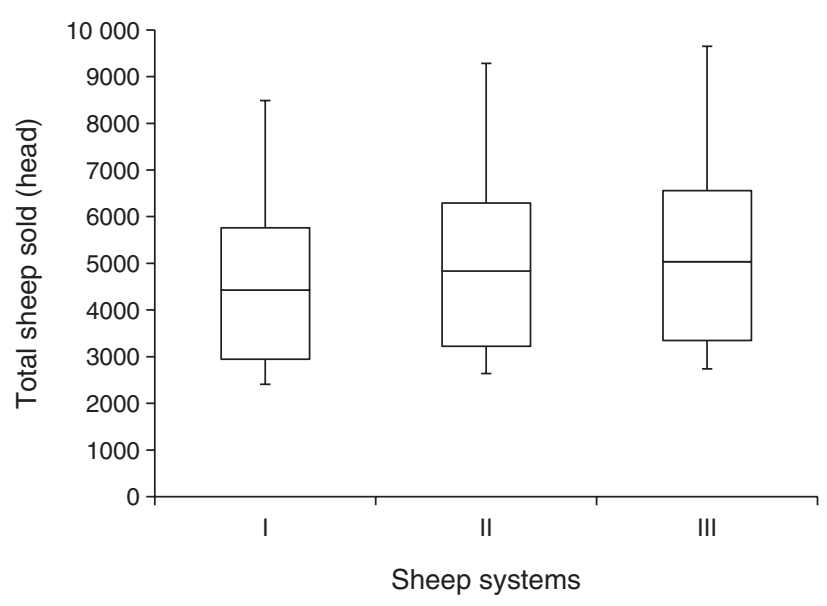

Fig. 8. Variability in simulated total number of sheep (lambs and ewes) sold per year for systems I, II and III. Boxes depict the 25th, 50th and 75th percentiles and whiskers the 0 and 100 percentiles over 111 years (1900-2011).

year respectively. Average chickpea yields on red and grey soils were 0.5 and $0.7 \mathrm{t} /$ ha.year, respectively.

\section{Livestock production}

Similar to crop production, as more land was dedicated to the grazing system, outputs increased; however, risk (distribution) of annual livestock production remained relatively constant. Average numbers of sheep sold for systems I, II and III were 4500, 4840 and 5040, respectively (Fig. 8). As the area of grazing increased, there was an upward shift in production. However, the distributions remained relatively constant, and therefore, the risk of livestock production was relatively constant for all three systems. The minimum production for the systems was 2200 fewer sheep sold than the median, and the maximum was $\sim 4400$ more sheep sold than the median.

\section{Whole-farm production risk and profitability}

The cumulative distribution of profits from systems I, II and III is presented in Fig. 9. These values include overheads for all three systems. System III, which does not crop, had reduced overheads, by $\$ 30000 /$ year, with less capital equipment and associated repairs. The opportunity cost of capital was also lower, and at $5 \%$, this equated to $\$ 6000 /$ year. Because the change in opportunity cost was so small, slightly to the left of the vertical opportunity cost line of $\$ 400000$, it was not represented in Fig. 9.

For the worst case scenario $(\psi=0 \%)$, losses were far greater with systems I and II (which include cropping). System I can result in a $\$ 260000$ loss, as opposed to system III with $\$ 122000$ loss $(\psi=0 \%)$. Likewise, under the best scenario, it was possible to almost double profits with system I $(\psi=100 \%)$ : $\$ 780000 v$ v. $\$ 440000$ for systems II and III. System I could result in higher profits than alternative systems $\geq 78 \%(\psi=100 \%-22 \%)$ of the time. The lower vertical line $(\psi=0-13 \%)$ of system III indicates the lower threshold of production (minimum sales) in drought years. The expected profits and probability of making a financial 


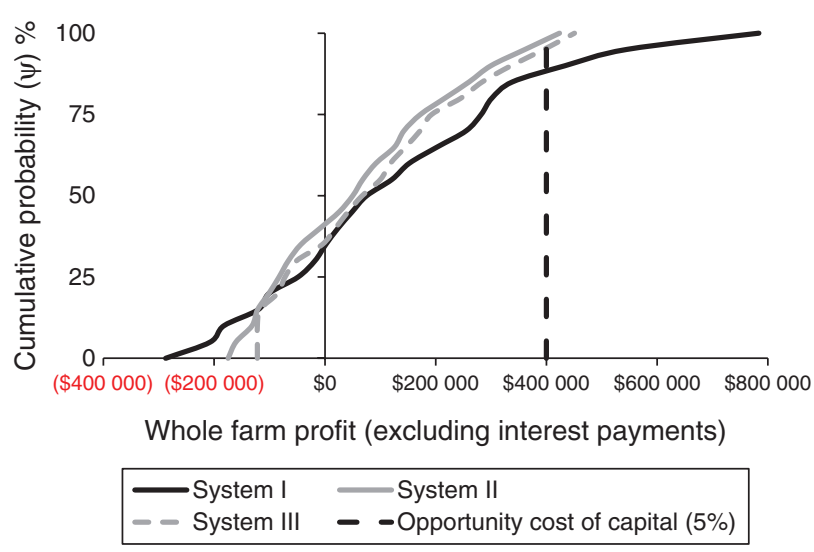

Fig. 9. Probability of profits per year at the whole farm level for systems I, II and III. The vertical line (\$400 000) indicates the opportunity cost of farm capital, being $\$ 8$ million at $5 \%$ per year. Worst case, best case and expected (median) outcomes are represented by $\psi=0,100$ and 50, respectively. Coefficient of variation for systems I, II, III was 2.67, 2.01 and 1.94, respectively.

loss are given in Table 4. Although system I offered higher profits, it also had the greater risk, where profits ranged from the lowest to the highest potential profits of all three systems. This was also reflected in the highest $\mathrm{CV}$ of 2.67 , compared with 2.01 and 1.94 for systems II and III, respectively. Additionally, system I and III have similar probabilities of breaking even ( $65 \%$ of years), with system II having the lowest chance of breaking even (59\% of years).

\section{Net present values}

Another risk to farmers is the chance of consecutive bad years. The probability of NPV over 10-year periods with a discount rate of $7 \%$ (which covers inflation, industry risk premium, and the farmer's time value of money) is given in Fig. 10.

The expected 10-year NPV and probability of making a financial loss are given in Table 5. The results indicate that system I offered the greatest expected profits, followed by system III and then system II, with 10-year NPVs of $\$ 763000$, $\$ 637000$ and $\$ 431000$, respectively. Under the worst case scenario, there was a $1 \%$ chance of incurring $>\$ 1$ million loss over a 10 -year period with system I, compared with a $\$ 0.5$ million loss with system III (Fig. 10). Both systems I and III have an 18\% chance of not breaking even over a 10 -year period, compared with the system II having a $22 \%$ chance (Table 5). It was possible to obtain NPVs of \$2.4 million and \$1.8 million for systems I and III over a 10-year period (Fig. 10). Although system I can result in the greatest negative NPV, system II offers the lowest expected 10 -year NPV, resulting in the highest relative risk $(\mathrm{CV}=1.45)$ of all the systems, compared with CV of $\sim 1.00$ for systems I and II.

\section{Sensitivity analysis of commodity prices}

Because Australian growers are price takers, it can be assumed that the price they receive is independent of production output at the farm scale. To investigate the sensitivity of the different production systems to downward price risk, both crop and sheep prices were reduced by $15 \%$. This resulted in expected 10 -year NPVs of $-\$ 8782,-\$ 137005$ and $\$ 106245$ for systems I-III,
Table 4. Expected annual profit $(\psi=50 \%)$, worst case $(\psi=0 \%)$ and best case $(\psi=100 \%)$ scenarios, probability of financial loss and coefficient of variation of farming systems

\begin{tabular}{lccc}
\hline & \multicolumn{3}{c}{ Production system } \\
& I & II & III \\
\hline $\begin{array}{c}\text { Expected (median, } \psi=50 \%) \\
\text { annual profit }(\pi)\end{array}$ & $\$ 75000$ & $\$ 50300$ & $\$ 67300$ \\
$\begin{array}{c}\text { Worst scenario }(\psi=0 \%) \\
\text { annual profit }(\pi)\end{array}$ & $-\$ 287627$ & $-\$ 174875$ & $-\$ 122008$ \\
$\begin{array}{c}\text { Best scenario }(\psi=100 \%) \\
\text { annual profit }(\pi)\end{array}$ & $\$ 783787$ & $\$ 423680$ & $\$ 450786$ \\
$\begin{array}{c}\text { Probability of a financial } \\
\text { loss }(<\$ 0)\end{array}$ & $35 \%$ & $41 \%$ & $35 \%$ \\
\begin{tabular}{l} 
Coefficient of variation \\
\hline
\end{tabular} & $2.01 \%$ & $2.67 \%$ & $1.94 \%$ \\
\hline
\end{tabular}

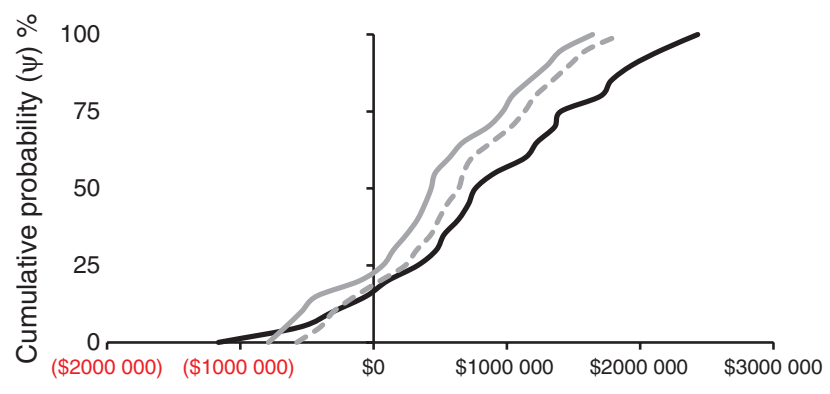

10-year NPV of profits (excluding interest payments)

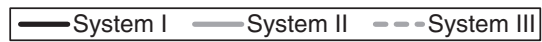

Fig. 10. Probability of discounted net present value (NPV) over a 10-year period with a discount rate of $7 \%$. Worst case, best case and expected (median) outcomes are represented by $\psi=0,100$ and 50, respectively.

Table 5. Expected 10-year net present value $(\psi=50 \%)$, probability of a loss and coefficient of variation of farming systems

\begin{tabular}{lccc}
\hline & \multicolumn{3}{c}{ Production system } \\
& I & II & III \\
\hline Expected 10-year NPV $(\psi=50)$ & $\$ 763000$ & $\$ 431000$ & $\$ 637000$ \\
Probability of financial loss $(<\$ 0)$ & $18 \%$ & $22 \%$ & $18 \%$ \\
Coefficient of variation & $1.00 \%$ & $1.45 \%$ & $0.99 \%$ \\
\hline
\end{tabular}

respectively (Fig. 11). Both systems I and II had a greater decrease than system III (Fig. 11), indicating that these systems were more sensitive to a percentage change in the price of crops than that of the price of sheep.

Price risk can be used to reflect both increases and decreases in output prices. If crop prices were to increase, farm profits would significantly increase for both systems I and II. Because less than half of the rotation (40\%) was used for wheat and chickpea production, the grazing component retarded the benefits of increased crop prices, but it also reduced the risk of cropping, as annual livestock production was less variable than annual crop production. However, real crop commodity prices, discounted for inflation, tend to decrease over time (Fig. 5); therefore, price risk was greater for systems I and II. 


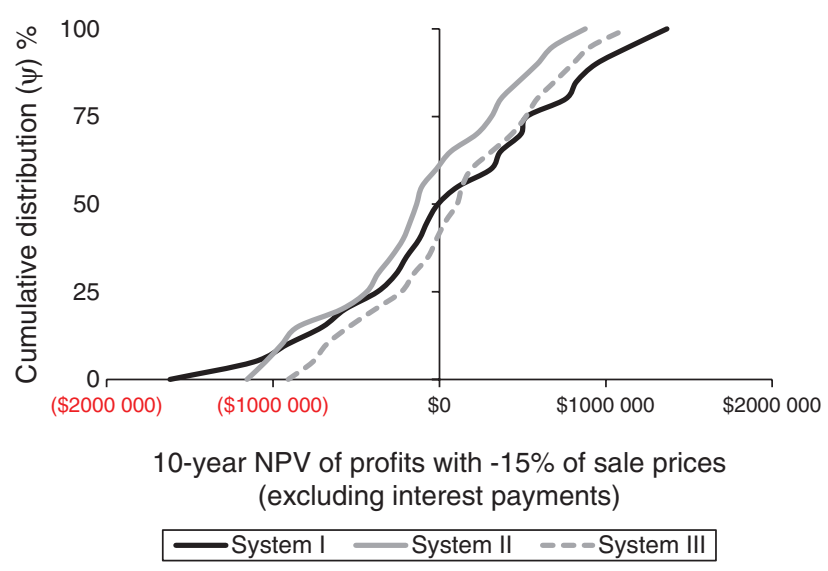

Fig. 11. Probability of the discounted net present value (NPV) of profits over a 10 -year period with a $15 \%$ decrease in crop and livestock prices, for the different production systems. Worst case, best case and expected (median) outcomes are represented by $\psi=0,100$ and 50, respectively.

\section{Discussion}

Current production decisions on the case-study farm are driven by past farming practices and other environmental considerations. The region of the farm has been identified as having a significant issue with declining pasture productivity and other environmental concerns including salinity risk (Biggs et al. 2010; Robinson et al. 2010). Soils used for crop production in this environment have shown declines in organic matter, degraded physical characteristics, increased erosion, as well as declining groundcover and nutrients (Silburn et al. 2007). Permanent pastures or pasture phases that include legumes and grasses may mitigate the effects of long-term cropping. If soil degradation due to extended cropping were included in the model, crop yields would decrease further and add an additional production risk. Based on the results produced in this case study, as well as other information, farmers in the region may be better informed about whether system I or III is better for them and their property. Soil degradation may also occur from overstocking, especially in drought-affected years. This case-study farm used conservative stocking rates of $<1$ DSE/ha, which is typical for this semi-arid subtropical region (Bell et al. 2014a). Compared with other sheep breeds, Dorpers are able to thrive under harsher conditions by utilising lowquality plant species; therefore, managers need to be particularly careful with stocking rates in harsher conditions to prevent the degradation of rangeland systems (Cloete et al. 2000; Alemseged and Hacker 2014). Conservative stocking rates reduce downside risk associated with the cost of supplementary feeding of livestock and reduce the risk of further soil degradation (Silburn et al. 2007; Bell et al. 2014a). At the time of the farm interview, weed herbicide resistance was not an issue on this farm. Long pasture phases in the case-study crop rotations have likely contributed to low herbicide resistance pressure (Monjardino et al. 2004).

Mixed farming systems are often employed to increase profits or decrease risk. Lawes and Kingwell (2012) found in Western Australian that higher portions of cropped area improved farm financial health. Bell and Moore (2012) on the other hand found that $40 \%$ of farm area devoted to cropping in New South Wales gave the lowest CV in whole-farm gross margins. However, neither study indicated the minimum portion of cropped land required to continue a cropping enterprise. Owing to both climatic and soil conditions, this case-study farm is unlikely to crop $40 \%$ of farm area sustainably. We investigated two mixed farming system scenarios: system I, with livestock and more intensive cropping; and system II, the current production system of livestock and minimal cropping. These systems allocated $30 \%$ and $5 \%$ of farm area to cropping, respectively. System III specialised solely in prime-lamb livestock production. The results of this case study support the theory that higher proportions of cropped area increase financial returns through economies of enterprise scale and increase probability of breaking even; however, downside risk and $\mathrm{CV}$ were also higher. More importantly, the case study indicates a shutdown point (minimum area of cropping), which results in both decreased profits and increased risk from cropping. Our case study found that the greatest expected profits are obtained with system I, followed by system III, and last system II (Fig. 9). Expected profits also indicate diseconomies of scale of system II, which required the same cropping capital equipment as system I but it had decreased utilisation of capital resources. There are many measures of risk; here we considered $\mathrm{CV}$, the probability of breaking even and the magnitude of the worst case scenario. Keeping in mind that system II (current production system) had a lower expected profit than system III (livestock only), the former also had a lower probability of breaking even, greater downside risk (worst case), lower upside risk (best case) and slightly higher CV (Fig. 9). Similar economic outcomes were shown for 10-year NPVs (Fig. 10). Therefore, in this case, the inclusion of a small amount of cropping (system II) was suboptimal to more intensive cropping (system I) and livestock specialisation (system III) (Hacker et al. 2009; Bell and Moore 2012). Whether production system I or III is best will depend on the farmer's required profits, level of risk aversion, and other considerations such as environmental impacts, farmer's age, number of dependent children and years remaining on the farm.

Changes in commodity prices can affect the on-farm decision about which commodity to produce; moreover, price volatility is also a source of risk to farm profitability. For many decades, a trend has existed in Australia towards increased crop production area and decreased livestock numbers; however, there is evidence that this trend may be slowing or even reversing (Bell and Moore 2012). Figure 5 shows that wheat and chickpea real prices (1991-2012) have tended to decrease, whereas sheep-meat real prices have significantly increased over the same period. The median annual real-price changes of all three commodities are similar (Fig. 6); however, meat-sheep is slightly higher, which is expected because it is also increasing at a faster rate than the crop prices (Fig. 5). Interestingly, wheat had the greatest variance (distribution); however, in $75 \%$ of years, this variance was lower than both sheep-meat and chickpea prices. If all commodity prices were decreased by $15 \%$ (downside risk), both cropping systems were affected more than the system specialising solely in livestock (system III) with respect to expected 10-year NPVs of profits (Figs 10 and 11). On the other hand, if crop prices increased (upside risk), then systems I and II would offer greater 
economic returns. Commodity price trends and sensitivity to downside crop price risk in regions with lower crop yields and emerging biophysical soil constraints indicates that seeking higher income by specialising in cropping and reducing livestock numbers may increase business risk (Hacker et al. 2009; Fisher et al. 2012; Bell et al. 2014b).

Other risk-reduction strategies of broadacre cropping include alternative fertiliser strategies, fodder crops for livestock production and crop insurance. This case-study farm operates on minimal inputs for relatively low production yields driven by low rainfall associated in semi-arid subtropical plains (Bell et al. 2014a). One option is to increase fertiliser rates to capture higher yields in the better years; however, the farmer indicated that, in their experience, the inclusion of chickpeas, lucerne and longer fallows results in sufficient nutrients to achieve the highest yields in most years and maximise profits. Forage supply risk is often driven by a mismatch between freshly grown forage and livestock demand (Bell et al. 2008). Rainfed lucerne is the only proven summer-active perennial legume in southern Australia, occurring when there is little rainfall and natural forage (Fisher et al. 2012). However, rainfed lucerne will have limited forage benefit in subtropical rangeland systems dominated by summer-active grasses and perennial shrubs (Bell et al. 2008). Crop insurance may also reduce risk; however, the insurance premiums are high relative to the low yields offered in this region owing to the frequency of low rainfall, flooding and frost. With most paddocks having elevated areas (Red Kandosol soils), some crop production will be achieved in most years. Therefore, the case-study farmer suggested that crop insurance is not financially viable for their production system.

For the reduction in cropping area from system I to system II, we did not change the capital owed for planting or spraying. With lower cropping intensity, it may be possible to liquidate this capital and use contractors; however, the property is remote and to rely on the availability of contractors when needed will further add to crop production risk. We did not investigate economies of scale of increasing total farm area; the property is currently $11000 \mathrm{ha}$, and an increase in area will have little effect in reducing overheads per hectare.

Not included in this analysis is the temporal benefit of holding land. Many farmers are capital-rich, but cash-poor. Equity creation by farmers often occurs from them holding land capital for long periods, during which inflation increases the nominal value of the property, but the initial bank loan remains relatively unchanged. For example, a $\$ 1$ million loan for land purchased may still be owed by the farmer to the bank for the full amount 30 years later, but the land value has increased by $\$ 3$ million. With the original loan remaining at $\$ 1$ million, the farmer now has $\$ 2$ million equity. Although the real value of the $\$ 2$ million is decreased by inflation, the farmer is still capital-rich. This equity creation over the long term must be considered when looking at the average annual net benefit of farming systems; some farmers may be willing to accept net annual losses with an aim of future capital gains on farm equity.

Results from this case-study analysis reflect some typical production systems in semi-arid mixed-farming systems in Queensland. However, every farm in every region is unique. Areas with higher rainfall are expected to be more favourable for crop production, and drier areas, which have soils of lower water-holding capacity, will be dominated by livestock meat production (Silburn et al. 2007; Bell et al. 2014a). Additionally, the sensitivity analysis compared proportional changes in output prices of wheat, chickpea, and prime lamb (Fig. 11). In reality, these commodity prices can move independently, and therefore, one commodity may become more profitable and help to offset the risk of producing the commodity.

Modelling analysis of mixed farming systems is important because it is difficult and expensive to compare different farming systems experimentally over time and at the wholefarm scale (Bell et al. 2008). Mixed farming systems tend to be more complex than systems specialising solely in either crops or livestock (Price and Hacker 2009). The whole-farm scale is particularly important due to the relationship between enterprises and it encompasses all incomes and expenses including overheads (Bell et al. 2008). Many livestock wholefarm models operate on seasonal patterns of an average year, with an aim of identifying the seasonal feed supply and demand; however, this provides little feed-risk information within highly variable climatic systems (Bell et al. 2008). Our analysis was undertaken at both the paddock and whole-farm level, based on APSIM analysis of crop and pasture production using current soil characteristics and historical climatic conditions (1900-2011). The case-study farmer indicated that mortality rates and finishing weights at year-end are relatively constant for sheep $\geq 1$ year of age, due to conservative stocking rates. The probability of twinning lambs surviving greatly reduces in years of low fodder production, as supported by Pitta et al. (2005). However, rates in that study were based on a shorter period of drought in New Zealand and using supplementary feed; therefore, those rates could not be used directly in our analysis. Some models operate on daily liveweight gain of livestock based on dry matter ( $\mathrm{kg} / \mathrm{ha}$ ) throughout the year (Bell et al. 2008). The inclusion of daily liveweight gain within our framework may further improve the analysis; however, it will result in more complex modelling. Our analysis of both profitability and risk can be beneficial for other mixed farming systems in other regions throughout Australia to assist both farmers and advisors in their on-farm short- and long-term decisions.

\section{Conclusion}

Farmers often adopt a mixed livestock and crop production system as a risk-spreading strategy; however, in doing this, farmers must also consider the profitability of the individual production systems as part of the whole farm enterprise. Of the three farming system scenarios investigated, we found that the greatest expected profits are obtained with system I (livestock and more intensive cropping), then system III (livestock only), and last system II (current production system of livestock and minimal cropping). The key driver of the lower profits of system II was the high overhead cost of capital to continue some cropping, with low annual cropping income. Under the worst case scenario, in years with low rainfall, system I had the greatest downside risk with far greater financial losses. Systems I and III had similar probabilities of breaking even, and better than system II, which incurs cropping overheads and limited cropping returns. Therefore, system II was less desirable than either system I or 
III according to all economic measures. In this case, the farmer would have been better to increase the cropping enterprise and use economies of scale of this enterprise to reduce overhead costs per hectare, or cease cropping and concentrate solely on the livestock enterprise. System I generated higher expected profits but it also had higher associated risk, and system III offered both lower returns and risk. Since undertaking this case study, the farmer has opted for the latter production system. This case study therefore helps farmers and advisors of semi-arid mixed farming enterprises to be better informed in making decisions at the paddock and whole-farm level in both the short and longer term, with respect to profit and risk. The method used in this paper can be applied to other mixed farms, nationally and internationally.

\section{Acknowledgements}

We thank Grain \& Graze II and GRDC for the part-funding used to undertake this research. In addition, we appreciate the support of Jeff and Wendy Betts, Tony Hamilton, Kristie Williams and Drs Andrew Biggs, Mark Silburn, and Geoff Cockfield for providing, unpublished data, reviewing the model and its outputs or reviewing the manuscript where required.

\section{References}

Alemseged Y, Hacker RB (2014) Introduction of Dorper sheep into Australian rangelands: implications for production and natural resource management. The Rangeland Journal 36, 85-90. doi:10.1071/RJ13034

Bardsley P, Haris M (1987) An approach to the econometric estimation of attitudes to risk in agriculture. Australian Journal of Agricultural Economics 31, 112-126. doi:10.1111/j.1467-8489.1987.tb00669.x

Bell LW, Moore AD (2012) Integrated crop-livestock systems in Australian agriculture: Trends, drivers and implications. Agricultural Systems 111, 1-12. doi:10.1016/j.agsy.2012.04.003

Bell LW, Robertson MJ, Revell DK, Lilley JM, Moore AD (2008) Approaches for assessing some attributes of feed-base systems in mixed farming enterprises. Australian Journal of Experimental Agriculture 48, 789-798. doi:10.1071/EA07421

Bell LW, Hayes RC, Pembleton KG, Waters CM (2014a) Opportunities and challenges in Australian grasslands: pathways to achieve future sustainability and productivity imperatives. Crop \& Pasture Science 65, 489-507. doi:10.1071/CP13420

Bell LW, Moore AD, Kirkegaard JA (2014b) Evolution in crop-livestock integration systems that improve farm productivity and environmental performance in Australia. European Journal of Agronomy 57, 10-20. doi:10.1016/j.eja.2013.04.007

Biggs AJW, Watling KM, Cupples N, Minehan K (2010) 'Salinity risk assessment for the Queensland Murray-Darling Region.' (Queensland Department of Environment and Resource Management: Toowoomba, Qld)

BoM (2012) SILO Data Drill System. Bureau of Meteorology Australia. Available at: www.longpaddock.qld.gov.au/silo/ (accessed June 2016).

Christodoulou N, Riddell J, Gray J (2001) 'Soil characterisation in the Balonne Shire through scientist-farmer collaboration.' Western Farming Systems Project Results Booklet QI01093. (QDPI/GRDC, Department of Agriculture and Fisheries: Brisbane, Qld)

Cloete SWP, Snyman MA, Herselman MJ (2000) Productive performance of Dorper sheep. Small Ruminant Research 36, 119-135. doi:10.1016/ S0921-4488(99)00156-X

Connor DJ (2004) Designing cropping systems for efficient use of limited water in southern Australia. European Journal of Agronomy 21, 419-431. doi:10.1016/j.eja.2004.07.004 de Haan C, Steinfeld H, Blackburn H (1997) Livestock and the environment: finding a balance. In 'Report of Study by the Commission of the European Communities, the World Bank and the governments of Denmark, France, Germany, The Netherlands, United Kingdom and The United States of America'. Ch. 3. (Directorate for Development, European Commission: Brussels)

DERM (2012) Water monitoring information portal. Queensland Department of Natural Resources and Mines, Queensland Government. Available at: http://watermonitoring.derm.qld.gov.au/host.htm (accessed June 2016).

DoA (2014) Australian Food Statistics 2012-13. Department of Agriculture and Water Resources, Canberra, ACT. Available at: www.agriculture. gov.au/ag-farm-food/food/publications/afs

Dunlop M, Turner G, Howden S (2004) Future Sustainability of the Australian Grains Industry. A consultancy report prepared for the Grains Council of Australia and Grains Research and Development Corporation. CSIRO Sustainable Ecosystems, Canberra, ACT. Available at: www.cse.csiro.au/ research/grainsfutures/.

FAO (2016) Producer prices - annual. Food and Agriculture Organization of the United Nations. Available at: http://faostat3.fao.org/download/P/PP/E (accessed June 2016).

Fisher J, Tozer P, Abrecht D (2012) Livestock in no-till cropping systems - a story of trade-offs. Animal Production Science 52, 197-214. doi:10.1071/ AN11123

Hacker RB, Robertson MJ, Price RJ, Bowman AM (2009) Evolution of mixed farming systems for the delivery of triple bottom line outcomes: a synthesis of the Grain \& Graze program. Animal Production Science 49, 966-974. doi:10.1071/AN09091

Keating BA, Carberry PS, Hammer GL, Probert ME, Robertson MJ, Holzworth D, Huth NI, Hargreaves JNG, Meinke H, Hochman Z, McLean G, Verburg K, Snow V, Dimes JP, Silburn M, Wang E, Brown S, Bristow KL, Asseng S, Chapman S, McCown RL, Freebairn DM, Smith CJ (2003) An overview of APSIM, a model designed for farming systems simulation. European Journal of Agronomy 18, 267-288. doi:10.1016/S1161-0301(02)00108-9

Lawes RA, Kingwell RS (2012) A longitudinal examination of business performance indicators for drought-affected farms. Agricultural Systems 106, 94-101. doi:10.1016/j.agsy.2011.10.006

Lawes R, Renton M (2015) Gaining insight into the risks, returns and value of perfect knowledge for crop sequences by comparing optimal sequences with those proposed by agronomists. Crop \& Pasture Science 66, 622-633. doi:10.1071/CP14185

Lloyd DL, Johnson B, O’Brien SM, Lawrence DN (2009) Action learning in partnership with Landcare and catchment management groups to support increased pasture sowings in southern inland Queensland. Animal Production Science 49, 907-915. doi:10.1071/EA08298

Makeham JP, Malcolm LR (1981) 'The farming game.' (Gill Publications: Armidale, NSW)

Monjardino M, Pannell DJ, Powles SB (2004) The economic value of pasture phases in the integrated management of annual ryegrass and wild radish in a Western Australian farming system. Australian Journal of Experimental Agriculture 44, 265-271. doi:10.1071/EA03050

Pitta DW, Barry TN, Lopez-Villalobos N, Kemp PD (2005) Effects on ewe reproduction of grazing willow fodder blocks during drought. Animal Feed Science and Technology 120, 217-234. doi:10.1016/j.anifeedsci. 2005.02.030

Powles SB, Preston C, Bryan IB, Jutsum AR (1996) Herbicide Resistance: Impact and Management. Advances in Agronomy 58, 57-93. doi:10.1016/ S0065-2113(08)60253-9

Price RJ, Hacker RB (2009) Grain \& Graze: an innovative triple bottom line approach to collaborative and multidisciplinary mixed-farming systems research, development and extension. Animal Production Science 49, 729-735. doi:10.1071/EA08306

RBA (2016) Historical database. Reserve Bank of Australia. Available at: www.rba.gov.au/statistics/historical-data.html (accessed June 2016). 
Rickert KG, Stuth JW, McKeon GM (2000) Modelling pasture and animal production. In 'Field and laboratory methods for grassland and animal production research'. (Eds L 't Mannetje, RM Jones) pp. 29-66. (CABI Publishing: New York)

Robinson JB, Silburn DM, Rattray D, Freebairn DM, Biggs A, McClymont D, Christodoulou N (2010) Modelling shows that the high rates of deep drainage in parts of the Goondoola Basin in semi-arid Queensland can be reduced with changes to the farming systems. Australian Journal of Soil Research 48, 58-68. doi:10.1071/SR09067
Schoeman SJ (2000) A comparative assessment of Dorper sheep in different production environments and systems. Small Ruminant Research 36, 137-146. doi:10.1016/S0921-4488(99)00157-1

Silburn DM, Robinson JB, Freebairn DM (2007) Why restore marginal cropland to permanent pasture? Land resource and environmental issues. Tropical Grasslands 41, 139-153. 